\title{
Early Bronze Age Painted Wares from Tell el-Abd, Syria: a Compositional and Technological Study
}

\author{
Giulia Russo $^{\mathrm{a} * 1}$, Silvia Amicone ${ }^{\mathrm{b}, \mathrm{c}}$, Christoph Berthold ${ }^{\mathrm{b}}$, Ruth Siddall $^{\mathrm{d}}$, Paola Sconzo $^{\text {a }}$ \\ ${ }^{a}$ Institute for Ancient Near Eastern Studies, Eberhard Karls Universität Tübingen, Tübingen, \\ Germany \\ ${ }^{\mathrm{b}}$ Competence Center Archaeometry Baden-Württemberg, Eberhard Karls Universität Tübingen, \\ Tübingen, Germany \\ ${ }^{\mathrm{c}}$ Institute of Archaeology, University College London, 31-34 Gordon Square, London WC1H 0PY, \\ United Kingdom \\ ${ }^{\mathrm{d}}$ Office of the Vice-Provost for Education \& Student Affairs, Gower Street, London WC1E 6BT, \\ United Kingdom
}

\begin{abstract}
The 'Euphrates Monochrome Painted Ware' (henceforth EMPW) is a ceramic style attested in the Middle Euphrates region in northern Syria at the beginning of the Early Bronze Age, ca. 2900 - 2700 BC. This style is not an isolated phenomenon; rather, it must be understood in the context of a general, albeit short-lived, re-introduction of painted ceramics into local assemblages of the whole Mesopotamia. In the present study, we investigate the technology and provenance of the painted pottery from Tell el-Abd (North Syria) and its relation to contemporary ceramics retrieved at this site. We apply a combination of macroscopic observations, ceramic petrography, and micro X-ray diffraction $\left(\mu-\mathrm{XRD}^{2}\right)$ in order to reconstruct the manufacturing process and to define the mineralogical and chemical composition of the sherds as well as of the pigments used for the painted decoration. The results of these analyses are then compared to the local geology in order to identify possible raw material sources. Based on the evidence, we provide the first interpretation of the provenance and technology of the Euphrates Monochrome Painted as well as unpainted ceramics of the assemblage.
\end{abstract}

\section{$\underline{\text { Keywords }}$}

Early Bronze Age

\footnotetext{
${ }^{1}$ Present address: Institute of Near Eastern Archaeology, Freie Universität Berlin, Germany

* Corresponding author. E-mail address: giulia.russo@fu-berlin.de
} 
Syrian Middle Euphrates

Painted pottery

Ceramic technology

Compositional analysis 


\section{Introduction}

In Upper Mesopotamia, the Early Bronze Age (EBA), roughly corresponding to the time span between 3100 and $2000 \mathrm{BC}$, constitutes a period of dramatic social, political, and economic change (Akkermans and Schwartz, 2003: 211-287; Cooper, 2006), that led to the rise and successive consolidation, at least in some areas, of a new urban model, which though alternate phases would have characterised the history of the region in the millennia ahead.

The pristine stage of the period (ca. 3100 - 2700 BC) follows, and is partly the result of, the collapse of the complex exchange network established in the LC 3-5/Uruk period of the second half of the fourth millennium (Rothman, 2001) and is marked by a trend towards regionalisation. Single areas/regions of Mesopotamia undertook different trajectories of development, as pointed out by their own local character in settlement pattern (nucleated versus sparse), strong differences in site size and territorial organisation (Wilkinson, et al., 2014) and, most importantly, by the emergence of a wide range of pottery styles quite different the one from the other. The latter still lay the foundation for most chronological assessments (Lebeau, 2014) for the proto-historic periods.

The tendency towards regionalisation is somehow substantiated by a short-term revival of the role of painted pottery as bearer of symbolic value. Over a wide area roughly extending from the Mediterranean coast (Amuq region) to the west to the Tigris basin to the east, and from the Taurus piedmont to the north to Lower Mesopotamia to the south, more or less at the same time painted decoration re-appeared on different kinds of vessels (Gerber, 2005: 81-103; Rova, 2014). This trend remains apparently unconnected with specific functional needs and has been scholarly interpreted as a renewed desire for the communities to express kin connections or intentionally mark their cultural identity; it has even been related to the appearance of new ethnic groups (Rova 2014).

In the present contribution, we will analyse one aspect of this regionalisation, the so-called EMPW, a pottery style attested in northern Syria along the middle course of the Euphrates river at the beginning of the EBA. Despite this ware being extensively studied from a purely typological point of view (Sconzo, 2013: 90-92, 216-219; 2015: 95), its technology has never been characterised. By combining macroscopic and archaeometric analyses, we aim to elucidate aspects related to provenance and manufacturing techniques, including the characterisation of the pigments. More specifically, our focus will be the material from Tell el-Abd, a small mound (ca. 3 ha) located in the area now flooded by the modern Lake Assad created at the close of the Tabqa Dam. The ceramics from this site have been systematically studied (Sconzo, 2013) and include one of the most representative groups of painted sherds of this type. 


\section{Tell el-Abd}

\subsection{The site}

The Middle Euphrates Valley is an approximately $600 \mathrm{~km}$ long strip of land stretching through the territories of modern southern Turkey and northern Syria, located between the Taurus ranges to the north and the alluvial plain of north-western Iraq to the south (Fig. 1a; Finkbeiner and Novák, 2015). Pleistocene terraces rising above the alluvial plain are characteristic of the physical environment of the valley. Yet, the local topographic features as well as the mean annual rainfall are not homogeneous along the course of the river; quite the opposite, they vary greatly when moving downstream, thus defining local 'topographic and landscape regions' (Wilkinson, 2007: 30). These have in turn contributed to the development of different modes of human settlement and ways of subsistence over time, with ancient communities accessing various ecological niches and resources (Cooper, 2006; Wilkinson, 2007: 27-46).

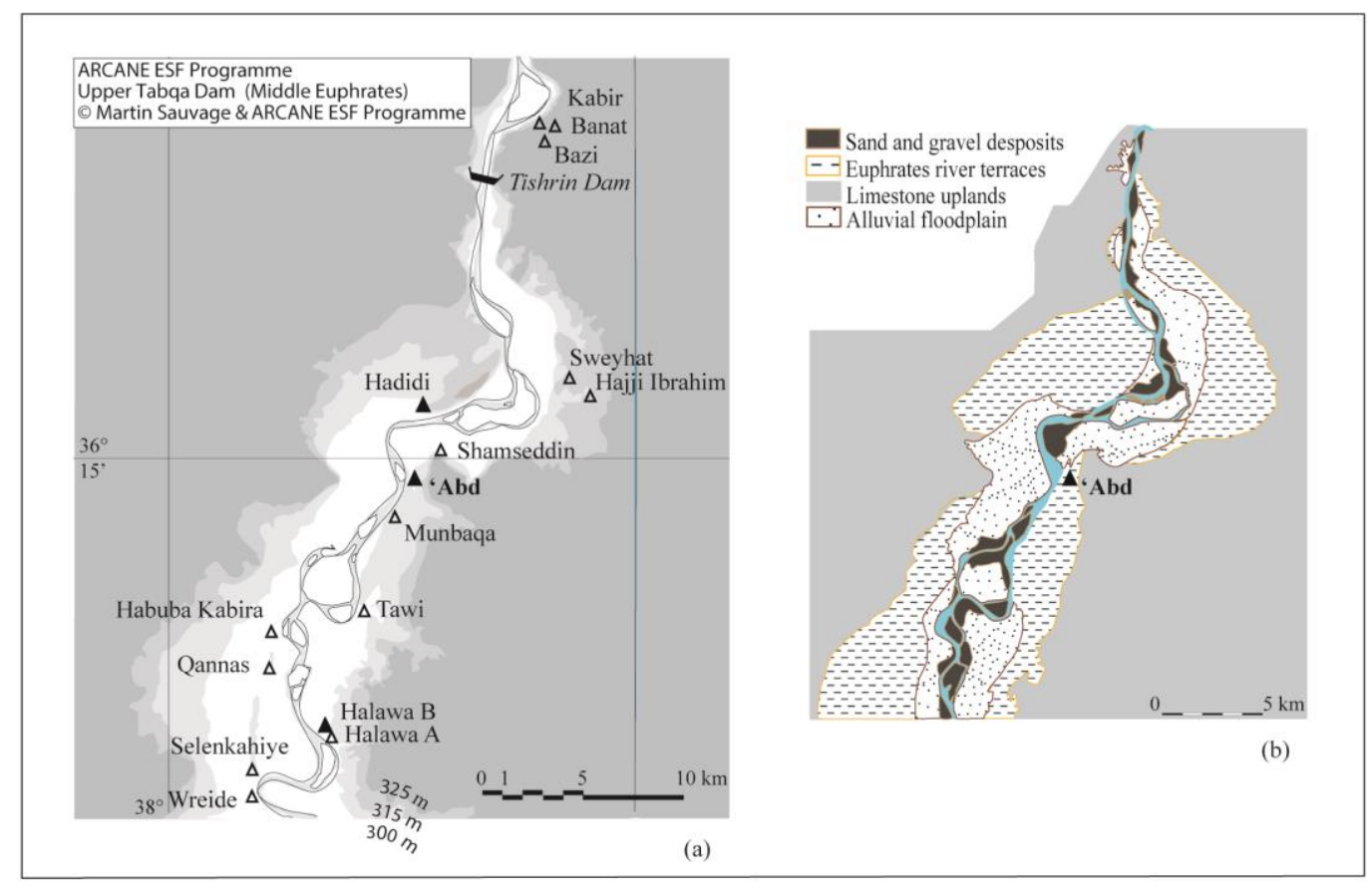

Fig. 1 The Middle Euphrates region in northern Syria. (a) Map showing the location of Early Bronze Age Tell el-Abd and contemporary sites (courtesy of M. Sauvage and the ARCANE Project). Sites yielding comparative Euphrates Monochrome Painted ceramics are indicated by the black triangle. (b) Simplified geomorphological map of the surroundings of Tell el-Abd (after Wilkinson et al. 2004: 18, fig. 2.2).

During the closing decades of the last century, the entire valley witnessed intensive archaeological explorations due to the construction of a series of dams along the river. These have unveiled its long history of human settlement from the Pre-Pottery Neolithic to the Late Classical period, with a particularly dense occupation in the Early Bronze Age (Cooper, 2006). 
Tell el-Abd occupied the top of a terrace situated on the east bank of the river at approximately $310 \mathrm{~m}$ a.s.l. and rising up to ca. $15.50 \mathrm{~m}$ above the floodplain (Sconzo, 2013: 11). This terrace was cut by a wadi (seasonal watercourse) to the south and overlooked the Euphrates to the west, the floodplain to the north, and the limestone uplands of the Jaziran Plateau to the east (Fig. 1b). First excavated by A. Bounni in the early 1970s (Bounni, 1979; Bounni, et al., 1974), the mound was flooded at the closing of the dam, but later re-emerged as a small peninsula for a short period of time during which renewed excavations were undertaken by a German mission of the Tübingen University led by U. Finkbeiner (Finkbeiner, 1994; 1995; 1997). The third millennium (Horizon 2 in the site periodization), corresponds to the period where the EMPW is found in the region. Horizon 2 at Tell el 'Abd features a town wall connected to a gate (Area I; Finkbeiner, 2015; Sconzo, 2013: 15-17) and two residential quarters located respectively at the south-eastern (Area III; Sconzo, 2013: 17-19) and at the western edge of the mound (Area II; Sconzo, 2013: 19-21). The C14 dates confirm a date of the associated occupation to cal. 2900 - 2700 BC (Deckers, et al., 2015; Sconzo, 2013: 156).

\subsection{The Early Bronze Age ceramic assemblage}

The macroscopic classification of the wares identified at Tell el-Abd by Paola Sconzo (2013: 80-98) constitutes the point of departure of the present research.
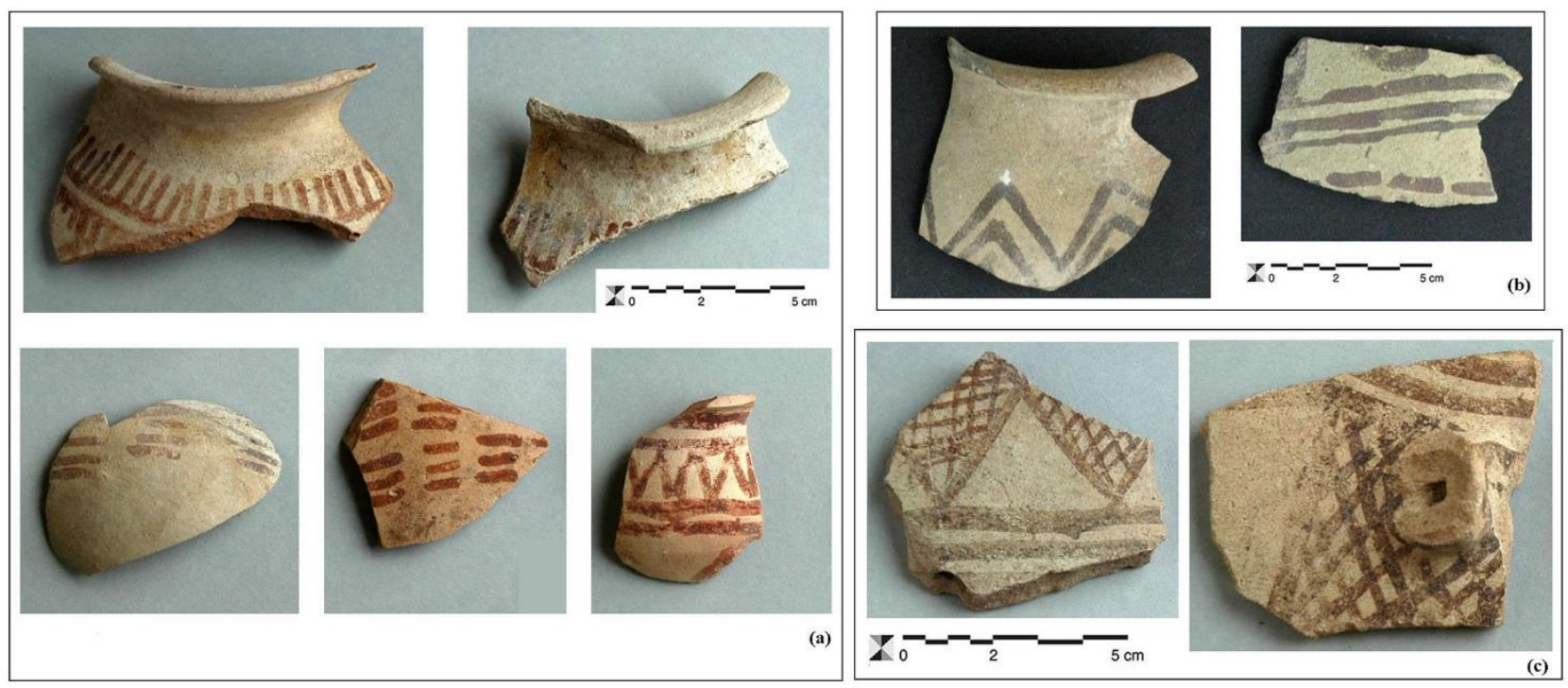

Fig. 2 Early Bronze Age painted ceramics from Tell el-Abd analysed in this study: (a) Euphrates Monochrome Painted Ware and (b) over-fired sherds and wasters; (c) Miscellaneous Painted Ware.

The EMPW, focus of our study, appears as a local tradition with a limited lifespan; it occurs predominantly in the region of Lake Assad between ca. 2900 - 2700 BC, after which it disappears (Sconzo, 2013: 90-92; 216-219; 2015: 95). From macroscopic analysis, the fabric is characterised as medium-textured with very small black or whitish mineral inclusions, and oxidized well-fired cores, 
pink to very pale brown in colour. Vessels seem to be, at least partially, wheel-made. The paint varies in colour from dark red or purple to reddish brown (Munsell 2.5 YR 4/6; 5 YR 4/4; 5 YR 5/6; 7.5 YR 5/4; Fig. 2a). It was applied over a fine slip by means of a brush and usually on the upper body of small, spherical jars with everted flaring rim and rounded bottom (Fig. 3). The distinctive decoration includes simple geometric elements such as zigzags, parallel horizontal lines, fringed bands, hatches, fences, and dots, combined together in standard motives usually defining a frieze around the shoulder of the vessel. Characteristic of this production is the low frieze around the belly of the vessel and made up of triple rows of hatched stripes (Fig. 3: 1490, 1491, 1503); the latter were possibly painted by means of a multiple-brush tool. Multiple zigzags with an upper fringed band or a lower dot-filling appear quite often, while a single zigzag line framed by double concentric plain bands occurs more rarely (Fig. 3: 540). Also frequent is the double or triple concentric band combined with either opposed fringes/short vertical strokes (Fig. 3: 1006, 1487, 1492) or pendent triangles (Fig. 3: 1489). At Tell el-Abd, 23 fragments of EMPW were identified and collected. In general, the execution of painted designs appears rather crude and careless; the presence of over-fired sherds and wasters suggest that at least some of the vessels were locally produced (Fig. 2b). Similar painted sherds were retrieved also at Qara Quzaq (Valdés Pereiro, 1995: 36-37, 40-42, fig. 32: 32-34), Halawa B (Lüth, 1989: 108, fig. 169: 102-104; Marro and Helwing, 1995), Tell Hadidi (Dornemann, 1988: figs. 5: 14, 10: 14-17, 24; 1990: pl. 21: 32), and Jebel Hammam (Sakal, 2011: fig. 15.16) (Fig. 1a).

Other wares considered in this study are the painted Ware C.4, henceforth MPW; the Simple Ware A.4; and the Cooking-Pot Ware D.2, abbreviated as CPW.

The MPW is another painted ware identified at Tell el-Abd; though recalling some technological traits of the EMPW, it features a completely different set of painted patterns and was kept separate from the latter (Fig. 2c, 3; Sconzo, 2013: 92-93).

The Simple Ware is the most common ware (over $80 \%$ of the diagnostics). Within this group, ware A.4 (henceforth abbreviated as SW) is the most frequent (814 fr.; Sconzo, 2013: 83-84). It has a fine to medium-textured fabric, with mineral inclusions all different colours. The sherds have generally a reddish core. Wet-smoothing or a creamy slip are the usual treatments for surface finishing (Fig. 3).

Coming to the CPW (Sconzo, 2013: 96-97), this has a coarse-textured mineral fabric, with large, visible inclusions. Firing is usually uneven with unoxidized cores and surfaces are generally buff. At the site, simple and cooking-pot wares share identical shapes, namely the short-necked jar with everted rim and rounded or flattened lip (Fig. 3). 


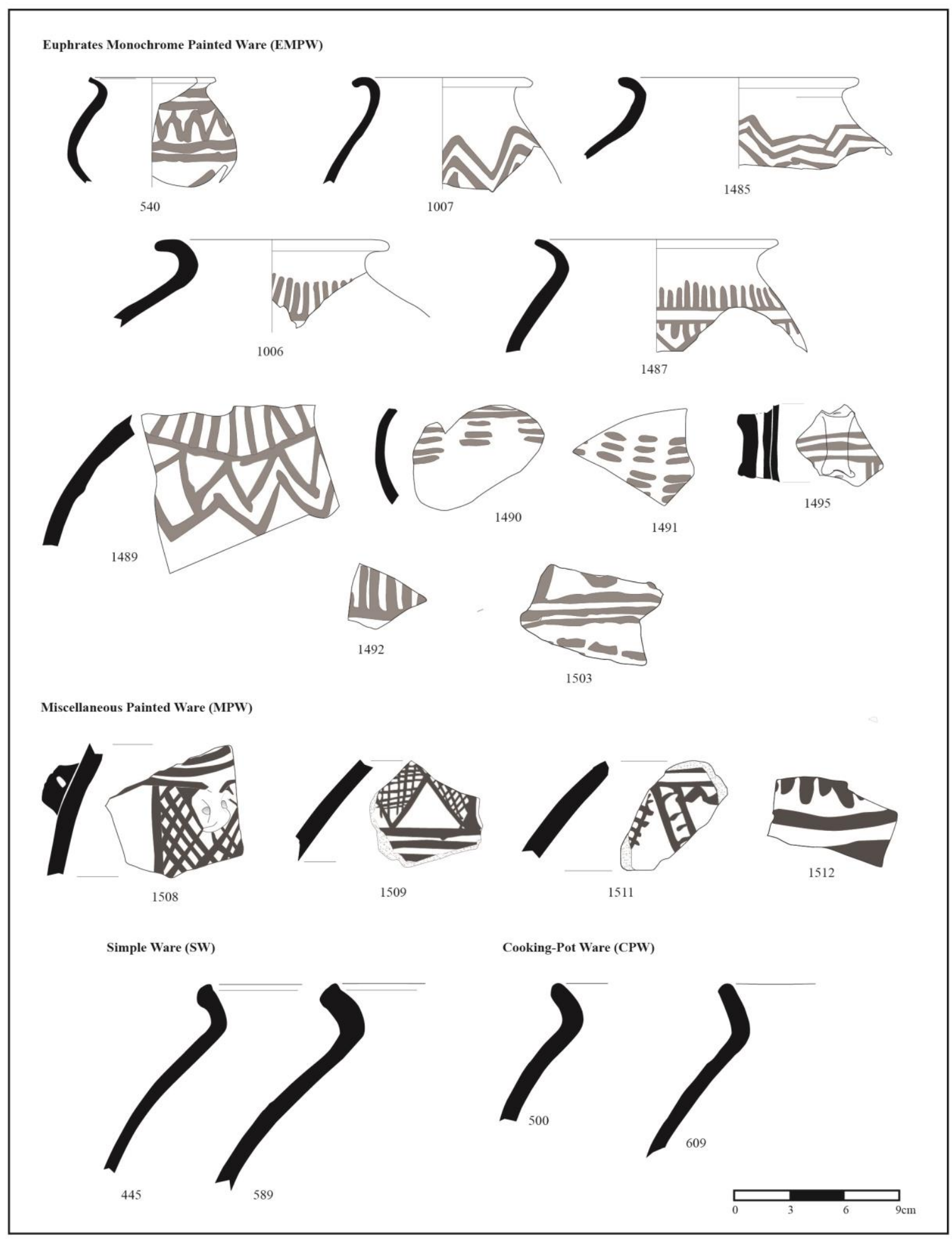

Fig. 3 Early Bronze Age ceramics from Tell el-Abd analysed in this study. The sample number corresponds to the catalogue number provided in Sconzo 2013.

The ceramic assemblage just described is kept at the University of Tübingen and was available for archaeometric studies. 


\section{Methods}

In order to characterize the manufacturing technology of the EMPW, we selected 11 well-preserved sherds, mainly fragments of the rim and the upper part of the vessel as well as body fragments displaying different decorations of this painted tradition. These represent more or less the $50 \%$ of the total amount of available sherds of this group. For an unbiased assessment of the relevant evidence, a small selection of other contemporary ceramics from the site was also analysed. This includes two sherds of the plain undecorated SW; two sherds of the CPW; and four other painted sherds of the MPW.

A macroscopic study was first carried out taking into account the macrotraces visible on the surface of the sherds to characterize different forming and finishing techniques. Unfortunately, due to the high fragmentation of the pottery samples it was not possible to reconstruct the complete chaîne opératoire of the vessels according to the methodology proposed by Roux (2016); our analysis has been thus confined only to the primary forming (e.g. pinching, drawing, coiling, wheel-throwing etc.) and finishing techniques of the upper portion of the vase.

Samples were subsequently examined through thin section petrography according to the standard procedure for ceramic analysis (Quinn, 2013: 23-33; Whitbread, 1989). Non-destructive and locally resolved X-ray diffraction analysis using a Bruker D8 Discover-GADDS microdiffractometer with a large 2-dimensional VANTEC-500 detector ( $\left.\mu-\mathrm{XRD}^{2}\right)$ were subsequently performed (Berthold, et al., 2015). The measurements were taken at a fixed incident angle of $10^{\circ}$ with the detector placed at $15^{\circ}$ and $40^{\circ}$ for a total measuring time of 10 minutes. Beam diameter of the primary X-ray beam was app. $300 \mu \mathrm{m}$ using a $500 \mu \mathrm{m}$ monocapillary X-ray optics with a $300 \mu \mathrm{m}$ pinhole at the exit. The resulting two detector images were combined in order to cover a $2 \vartheta$ angle from app. $10^{\circ}$ to $60^{\circ}$ and a diffraction pattern was calculated from the overlapping two detector images. Crystalline phases were identified using the PDF-2 database from ICDD (International Centre of Diffraction Data).

\section{Macroscopic, petrographic, and geochemical classification}

Given that no complete profiles of the wares analysed in this study have been found at Tell el-'Abd, all observations on forming techniques were limited to the preserved rim and upper part of the vessels of this study. Sherds of MPW, being only body fragments which couldn't be clearly ascribed to a specific morphological type, were not included in the macroscopic analysis for characterizing forming techniques. Based on overall appearance, the presence of round bases for the EMPW and possibly the CPW has been postulated on the basis of parallels with similar pieces found at other sites and, in 
general, to the almost complete lack of flat or pointed bases in the pottery repertoire of the period at the site (Sconzo 2013: 23).

Vessels were usually built in two parts, i.e. the rim and the spherical body, and then assembled together later, at the leatherhard stage. The body was made by coiling, as suggested by the irregular thickness of the section and the horizontal cracks in the point in which the coils were attached (Fig. 4); rims were seemingly coiled as well, but then refined on the wheel and attached while on the same device (or the other way round). The latter action results in the presence of thin and even horizontal sub-parallel striations along the interior and exterior of the neck and the rim (Fig. 4). Some specimens show localized, uneven over thickness on the interior of the neck at its junction with the upper portion of the body, likely due to the superimposition of the coils when forming the vessel or the addition of an extra coil to join neck and body (Fig. 4).

Based on the observation at the optical microscope, samples were classified into petrographic groups according to the nature, abundance, size, shape, and distribution of the inclusions, as well as to the colour and homogeneity of the clay matrix, and the nature of the voids. Two petrographic groups

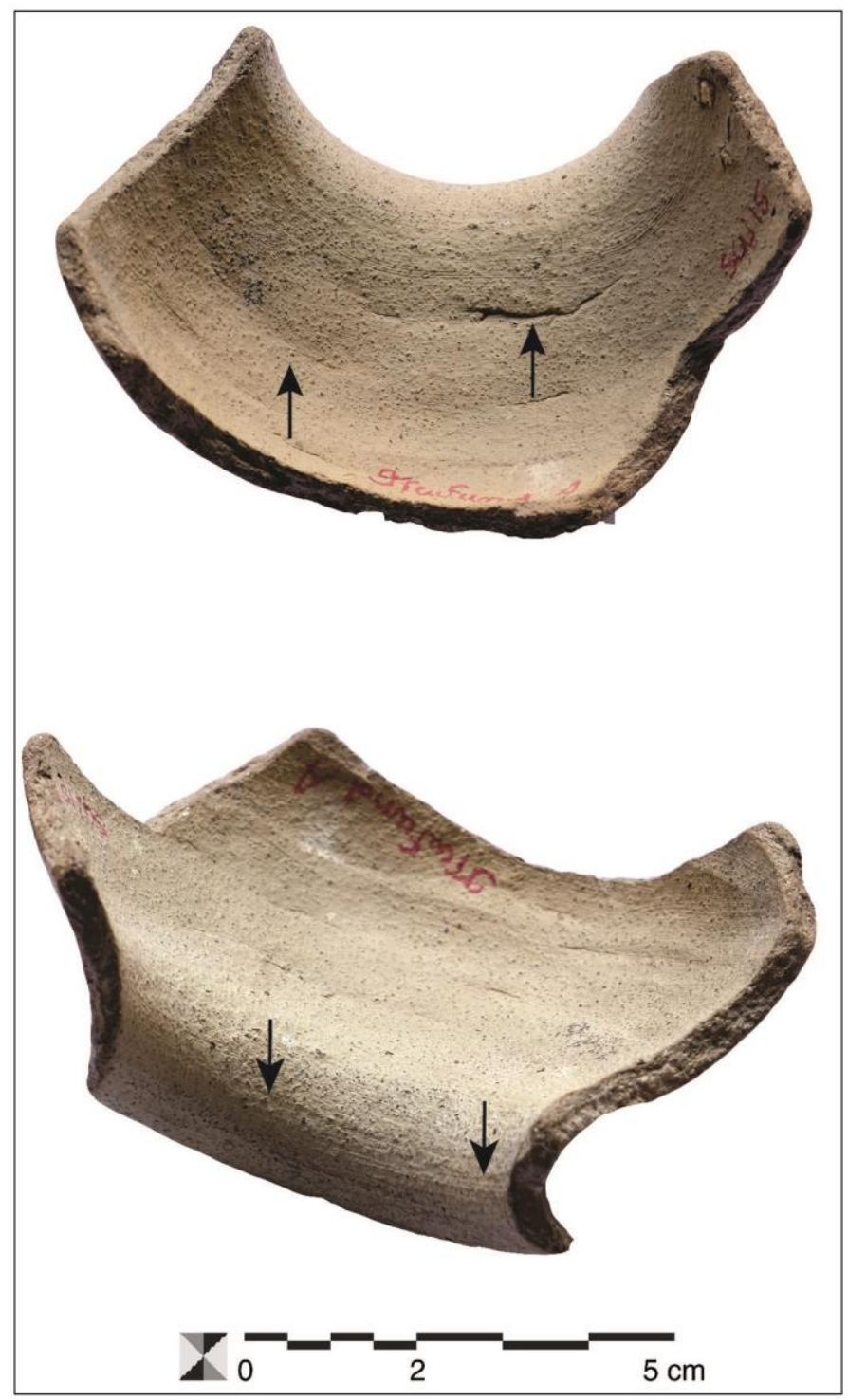

Fig. 4 Macrotraces on a sherd of Euphrates Monochrome Painted Ware showing evidences for a mixed manufacturing technique including forming by coiling and shaping on a slow wheel. Top: the irregular sherd profile, the horizontal cracks at the joints of the coils, and the localized, uneven over thickness on the interior of the neck at the junction with the rim are evidences of coiling as forming technique. Bottom: the thin, even horizontal sub-parallel striations along the interior of neck and rim result from the shaping of the vessel on a slow wheel. (Photo: Tobias Kiemle).

were defined for this assemblage, respectively the Pyroxene Fabric (Fabric A) and the Calcite Tempered Fabric (Fabric B). 

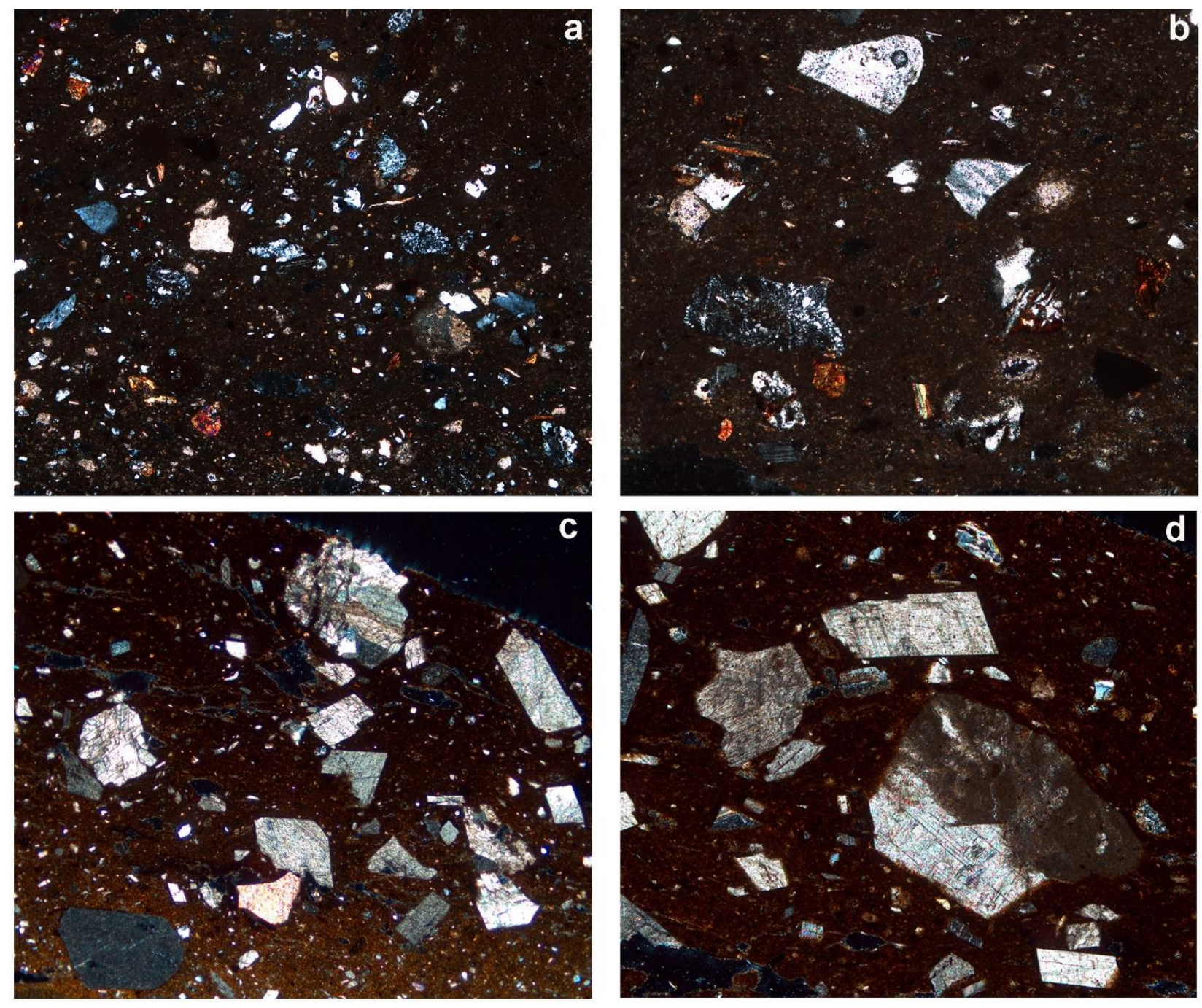

Fig. 5 Photomicrographs of the petrographic fabrics detected in the Early Bronze Age ceramic thin sections from Tell el-Abd examined in this study: (a, b) Pyroxene Fabric and (c, d) Calcite Tempered Fabric. All images taken in crossed polars. Image width $=4 \mathrm{~mm}$ (Fig. 5a, d), $2 \mathrm{~mm}$ (Fig. 5b), and $8 \mathrm{~mm}$ (Fig. 5c).

Fabric A contains predominantly fragments of volcanic rocks (Fig. 5a/b). Euhedral to anhedral crystals of quartz, plagioclase and clinopyroxenes are also common. Fragments of metamorphic rocks are rare, serpentinite and calcite also occur rarely. The matrix is deep brown to almost black in colour and shows no optical activity. The textural and compositional characteristics of this fabric suggest the employment of a secondary calcareous clay source. Relic coils visible in all samples indicate the use of coiling as primary forming technique. Fabric A includes 17 of the analysed samples; these belong in turn to three different wares, defined as EMPW (11 sherds), SW (two sherds) and MPW (four sherds) (Table 1).

Fabric B displays abundant calcite inclusions (Fig. 5c/d). It appears that the clay was tempered with angular, well-sorted calcite fragments probably deriving from limestone. Under crossed polarizing light, the clay matrix is yellow-brown to deep orange-brown in colour and shows moderate optical activity, which suggests a low firing temperature. Also, the presence of relic coils indicates 
coiling as the main forming technique. Only two thin sections are classified into this petrographic group; they both belong to sherds of CPW (Table 1).

\begin{tabular}{|c|c|c|c|}
\hline Sample & Ware group & Petrographic group & Reference (Sconzo 2013) \\
\hline 445 & SW A.4 & Pyroxene Fabric A & Pl. 41: 445 \\
\hline 500 & CPW D.2 & Calcite-Tempered Fabric B & P1. 46: 500 \\
\hline 540 & EMPW C.3 & Pyroxene Fabric A & Pl. 48: 540; 131: 540 \\
\hline 589 & SW A.4 & Pyroxene Fabric A & Pl. 53: 589 \\
\hline 609 & CPW D.2 & Calcite-Tempered Fabric B & Pl. 55: 609 \\
\hline 1006 & EMPW C.3 & Pyroxene Fabric A & Pl. 89: 1006; 131: 1006 \\
\hline 1007 & EMPW C.3 & Pyroxene Fabric A & Pl. 89: 1007; 131: 1007 \\
\hline 1485 & EMPW C.3 & Pyroxene Fabric A & Pl. 131: 1485 \\
\hline 1487 & EMPW C.3 & Pyroxene Fabric A & Pl. 131: 1487 \\
\hline 1489 & EMPW C.3 & Pyroxene Fabric A & Pl. 131: 1489 \\
\hline 1490 & EMPW C.3 & Pyroxene Fabric A & Pl. 131: 1490 \\
\hline 1491 & EMPW C.3 & Pyroxene Fabric A & Pl. 131: 1491 \\
\hline 1492 & EMPW C.3 & Pyroxene Fabric A & Pl. 131: 1492 \\
\hline 1495 & EMPW C.3 & Pyroxene Fabric A & Pl. 131: 1495 \\
\hline 1503 & EMPW C.3 & Pyroxene Fabric A & Pl. 131: 1503 \\
\hline 1508 & MPW C.4 & Pyroxene Fabric A & Pl. 131: 1508 \\
\hline 1509 & MPW C.4 & Pyroxene Fabric A & Pl. 131: 1509 \\
\hline 1511 & MPW C.4 & Pyroxene Fabric A & Pl. 131: 1511 \\
\hline 1512 & MPW C.4 & Pyroxene Fabric A & Pl. 131: 1512 \\
\hline
\end{tabular}

Table 1 Details of the 19 analysed Early Bronze Age pottery sherds from Tell el-Abd with macroscopic ware group and petrographic group classification. 
The following step of this study was the characterization of the mineralogical composition of the sherds surfaces and pigments by means of $\mu-\mathrm{XRD}^{2}$. When selecting the samples, we picked the fragments showing different hues of red and brown in order to get an assessment of the whole range of pigment colours obtained by ancient potters. The matrix of all the examined sherds had a more or
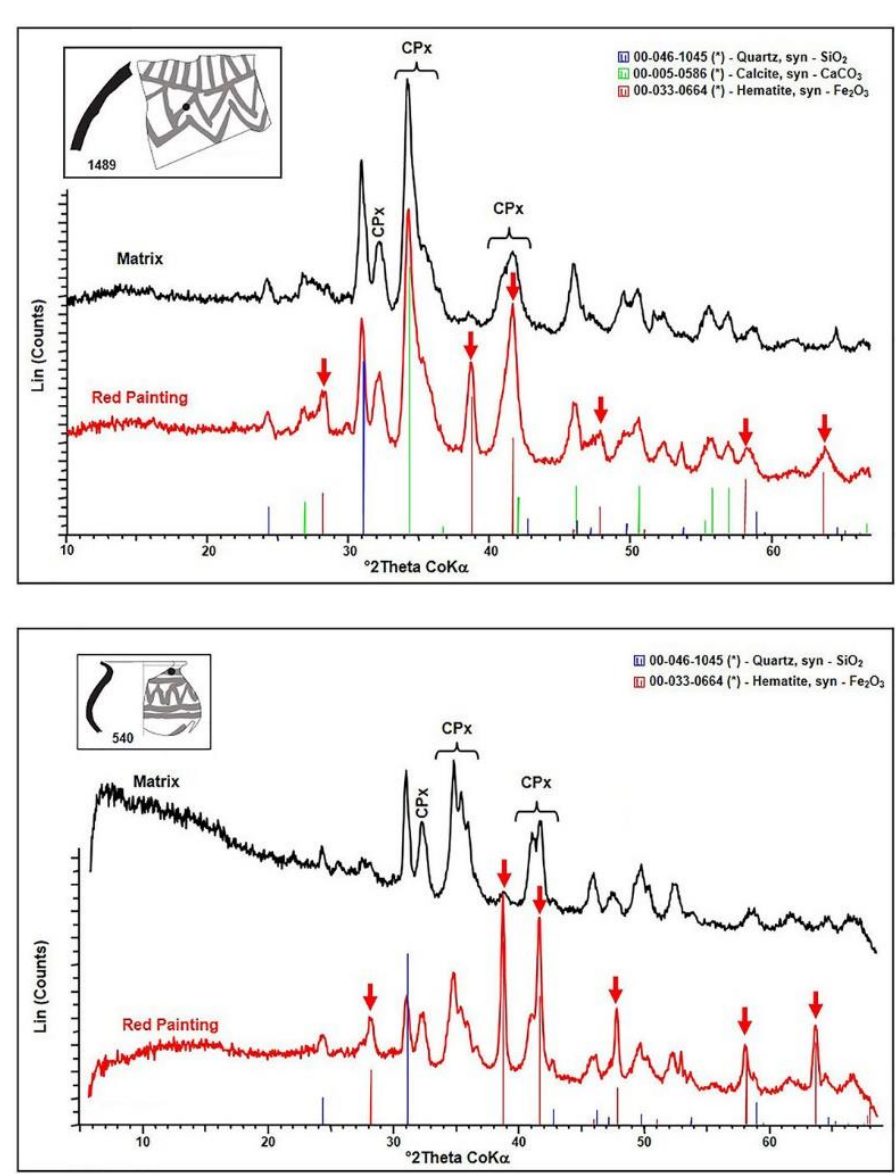

Fig. 6 Diffractograms from $\mu-X^{2} D^{2}$ analysis of two sherds of Euphrates Monochrome Painted Ware from Tell el-Abd: (a) sherd 1489 and (b) sherd 540. In the box with the drawing of the sample, the black dot indicates the point on the sherd's surface where the measurement was taken. less similar mineral composition with quartz and typical reflections for clinopyroxene (CPx; Fig. 6a/b). The calcite reflection visible in the diffraction pattern of some samples (Fig. 6a) can be due to the calcareous nature of the employed clay as well as to postdepositional infiltration of secondary calcite in the clay body (Quinn 2013: 207). The $\mu$ $\mathrm{XRD}^{2}$-measurements of the red (samples 540, 1487, 1489) and dark brown painted decoration (samples 1508 and 1509) showed characteristic reflections for hematite (Fig. $6 a / b)$. It is likely that readings from the underlying clay matrix are also included in the diffraction pattern of the decoration because of the thinness of the painted layer. $\mathrm{X}$-ray analyses of the black pigment from over-fired sherds and wasters are still in progress and will be the object of a future publication.

\section{Ceramic provenance and manufacturing}

The macroscopic, petrographic, and geochemical analyses revealed the low variability of the ceramic assemblage from Tell el-Abd in terms of pottery manufacturing and clay recipes. Ancient potters seem to have used similar forming and finishing techniques and a limited range of raw material sources for producing their vessels. Based on the examination of the macrotraces, it was possible to reconstruct only one fashioning technique, with vessels formed by coiling and finished by means of a slow wheel.

Two main petrographic groups were identified at the site, namely the Pyroxene Fabric A for the EMPW, MPW, and SW, and the Calcite Tempered Fabric B characteristic of the CPW. Such a 
differentiation could be connected to the different use and expected performance of the vessels. A geological map of the area (Wilkinson, et al., 2004: 18, fig. 2.2) was used to identify which available raw sources were most likely exploited by ancient potters. In the absence of geological samples from the surroundings of Tell el- Abd, it is difficult to locate, with precision, sources of raw material employed in the pottery production process. Yet, comparisons between the fabrics and the local geomorphology suggested that the raw materials used are indeed compatible with the local geology. Based on textural and compositional features, we propose the employment of secondary clays for Fabric A. Tell el- Abd occupies the top of a Pleistocene terrace of the main terrace complex of the Euphrates Valley (Fig. 1b). This complex originates from the erosive action of the river on the adjacent limestone and results from the superimposition of gravel deposits (igneous, metamorphic, and sedimentary rocks brought downstream from Anatolia, as well as sand and silt of local origin) and, in the uppermost layers, wash deposits from the surrounding terraces and hills (Wilkinson, et al., 2004: 19-20). In this region, the Euphrates plays a crucial role in the formation of secondary clay deposits, available in abundance and easily accessible from Tell el- Abd. In light of this and following the assumption that raw materials for ancient ceramics were collected in close proximity to the production locale (Arnold, 1985: 32ff.), it might be suggested that ancient potters at Tell el- Abd utilised the resources available in their immediate surrounding environment. Furthermore, the EMPW retrieved at the site included a number of over-fired sherds (29\%) and wasters with greenish paste (21\%). Wasters are generally seen as evidence for on-site ceramic production (Rice, 1987: 179-180). Localized over-firing might accidentally happen during firing, but this does not imply that the vessel will be discarded; quite the contrary, it will be used if it retains its functionality, but it is unlikely to be transported over large distances from its location of manufacture (Rye, 1981: 8). Based on this evidence, we propose a local production at Tell el- 'Abd of the Fabric A group including EMPW, MPW, and SW.

As for the Calcite Tempered Fabric B, its clay differs from the one of the Pyroxene dominant Fabric A since it lacks volcanic rocks fragments. It is possible that ancient potters resorted to a different clay for making cooking-pots and subsequently deliberately added crushed calcite in order to improve the resistance to thermal stress of the vessels (Rice, 1987: 229; Roux, 2016: 58; Rye, 1976). EBA cooking-pots from the Middle Euphrates region seem to have been tempered with calcite (Cooper, 2006: 183), unfortunately no petrographic analyses of these sherds are available at the moment. Interestingly, in our region calcite-tempered cooking-pots appear also in later periods, as shown by petrographic investigations of the Middle Bronze Age (ca. 1900 - 1500 BC) vessels from Tell Hadidi, ca. 4 km north-west of Tell el-'Abd on the western bank of the Euphrates (Mason and Cooper, 1999: 142, 145). This petrofabric was considered 'exotic' because its clay didn't seem to 
match the local Euphrates geology. As previously written, the use of such a fabric for cooking-pots might be connected to the need for vessels efficiently withstanding heat; yet, the persistence of this pottery recipe in the Middle Euphrates region over approximately 1000 years might also imply a longterm transmission of knowledge of pottery making.

Returning to the EMPW, the red painted decorations characterising the fragments of this group varied in shades from dark red to reddish brown. The $\mu-\mathrm{XRD}^{2}$-measurements of this paint highlighted the presence of hematite. This can be linked to the employment for the painted decoration of an ochre (typically a mixture of goethite and hematite which transforms into pure hematite during firing) or a pure hematite applied as such before firing (Eastaugh, et al., 2008: 189). Alternatively, an iron-rich illitic clay could have been employed, as hematite could develop during the oxidizing firing of this type of clay (Cuomo di Caprio, 2007: 307-309). For the time being, it is however not possible to assess how this ochre was prepared and whether water or clay were used in its formulation. The red painting varies in thickness and intensity among the samples here considered. In some sherds it has been completely washed out (either during use or following deposition) leaving only a faint trace, while in others it is still quite thick either on the whole surface or at particular spots, such as along the neck below the everted rim of the vessel. As for the sherds with a black decoration, further analyses are in progress in order to better assess the mineralogical composition of these pigments.

\section{Conclusions}

This study has shown that a technological approach combining macroscopic observations, ceramic petrography, and non-destructive $\mu-\mathrm{XRD}^{2}$ is crucial for the reconstruction of provenance and aspects of manufacturing as well as the characterisation of pigments of ancient pottery (Quinn, 2013; Tite, 1999). The examination of the macrotraces revealed that vessels with different macroscopic fabrics and functions were manufactured employing the same forming techniques. By defining compositional groups and comparing them to the local landscape, it was possible to suggest a local, i.e. Middle Euphrates, origin for the painted and plain pottery retrieved at Tell el-Abd. Moreover, the evidence, together with the presence of by-products of pottery making (over-fired sherds and wasters), support the proposal of a local, on-site production for the EMPW. Taken together, our results validate the original macroscopic classification of the sherds and allowed to ascertain commonalities in raw materials and manufacturing among different ceramic products. Finally, it is hoped that additional, future archaeometric analyses of EBA assemblages from the Middle Euphrates will enrich our knowledge of the ceramic technology of this period and further contribute to our understanding of the cultural contacts amongst the sites and communities living at the time in the area. 


\section{Acknowledgements}

The research presented in this paper was made possible thanks to the support and encouragement of different people and institutes. We are grateful to Uwe Finkbeiner for kindly providing access to the Tell el-Abd ceramics analysed in this study, which are kept at the Institute for Ancient Near Eastern Studies of the Eberhard Karls Universität Tübingen, Germany. Petrographic and mineralogical analyses took place in the Competence Center Archaeometry Baden-Württemberg (CCA-BW) of the Eberhard Karls Universität Tübingen. We would like to express our gratitude to the Excellence initiative of the Eberhard Karls Universität Tübingen and the Ministry for Science, Research and Art of Baden-Württemberg for the generous support provided to this research. A special thank to Mike Lewis for checking the language.

\section{References}

Akkermans, P.M.M.G., Schwartz, G.M., 2003. The archaeology of Syria: from complex hunter-gatherers to early urban societies (c. 16,000-300 BC), Cambridge University Press, Cambridge.

Arnold, D.E., 1985. Ceramic theory and cultural process, Cambridge University Press, Cambridge.

Berthold, C., Keuper, M., Bente, K., 2015. Dealing with antique objects: non destructive X-ray microdiffraction coupled with $\mu$-Raman spectroscopy and $\mu$-X-ray fluorescence, in: Greiff, S., Kronz, A., Schlütter, F., Prange, M. (Eds.), Archäometrie und Denkmalpflege 2015. Jahrestagung an der JohannesGutenberg-Universität Mainz 25.-28. März 2015, Metalla Sonderheft 7, pp. 24-26.

Bounni, A., 1979. Preliminary report on the archaeological excavations at Tell al-'Abd and 'Anab al-Safinah (Euphrates) 1971-1972, in: Freedman, D.N. (Ed.), Archaeological Reports from the Tabqa Dam ProjectEuphrates Valley, Syria, Annual of the American Schools of Oriental Research 44, Cambridge, pp. 49-62.

Bounni, A., Saliby, N., Toueir, K., Zaqzuq, A., 1974. First report on the excavations at Tell al-'Abd and 'Anab Safina (Euphrates), Annales Archéologiques Arabes Syriennes 24, 53-74.

Cooper, L., 2006. Early Urbanism on the Syrian Euphrates, Routledge, New York.

Cuomo di Caprio, N., 2007. Ceramica in archeologia 2. Antiche tecniche di lavorazione e moderni metodi di indagine, L'erma di Bretschneider, Roma.

Deckers, K., Drechsler, P., Sconzo, P., 2015. Radiocarbon Chronology, in: Finkbeiner, U., Novák, M., Sakal, F., Sconzo, P. (Eds.), Associated Regional Chronologies for the Ancient Near East. Middle Euphrates, Brepols, Turnhout, pp. 401-421.

Dornemann, R.H., 1988. Tell Hadidi: One Bronze Age site among many in the Tabqa Dam salvage area, Bulletin of the American Schools of Oriental Research 270, 13-43.

Dornemann, R.H., 1990. The beginning of the Early Bronze Age in Syria in the light of recent excavation, in: Matthiae, P., van Loon, M.N., Weiss, H. (Eds.), Resurrecting the Past. A Joint Tribute to Adnan Bounni, Nederlands Instituut voor het Nabije Oosten, Leiden, pp. 85-100.

Eastaugh, N., Walsh, V., Chaplin, T., Siddall, R., 2008. Pigment Compendium. A Dictionary and Optical Microscopy of Historical Pigments, Routledge, London.

Finkbeiner, U., 1994. Abd, in: Weiss, H. (Ed.), Archaeology in Syria, American Journal of Archaeology 98, pp. 116-117.

Finkbeiner, U., 1995. Tell el- Abd: Vorläufiger Bericht über die Ausgrabungen 1992-1993, Damaszener Mitteilungen 8, 51-83. 
Finkbeiner, U., 1997. Abd, in: Weiss, H. (Ed.), Archaeology in Syria, American Journal of Archaeology 101, pp. 97-100.

Finkbeiner, U., 2015. A Palace from the Early Third Millennium in Tell el- ${ }^{-}$Abd (Raqqa Province), in: Ciafardoni, P., Giannessi, D. (Eds.), From the Treasures of Syria. Essays on Art and Archaeology in Honour of Stefania Mazzoni, Nederlands Instituut voor het Nabije Oosten, Leiden, pp. 3-12.

Finkbeiner, U., Novák, M., 2015. Introduction, in: Finkbeiner, U., Novák, M., Sakal, F., Sconzo, P. (Eds.), Associated Regional Chronologies for the Ancient Near East. Middle Euphrates, Brepols, Turnhout, pp. 1-16.

Gerber, J.C., 2005. Hassek Höyük III Die frühbronzezeitliche Keramik, Ernst Wasmuth Verlag, Tübingen.

Lebeau, M., 2014. Ceramics, Associated Regional Chronologies for the Ancient Near East Interregional, Brepols, Turnhout.

Lüth, F., 1989. Tell Halawa B, in: Orthmann, W. (Ed.), Halawa 1980 bis 1986, Vorläufiger Bericht über die 4-9 Grabungskampagne, Saarbrücker Beiträge zur Altertumskunde 52, Bonn, pp. 85-109.

Marro, C., Helwing, B., 1995. Vers une chronologie des cultures du Haut-Euphrate au troisième millénaire Untersuchungen zur bemalten Keramik des 3. Jt. am oberen und mittleren Euphrat, in: Finkbeiner, U., Dittmann, R., Hauptmann, H. (Eds.), Beiträge zur Kulturgeschichte Vorderasiens. Festschrift für Rainer Michael Boehmer, Philipp von Zabern Verlag, Mainz am Rhein, pp. 341-383.

Mason, R.B., Cooper, L., 1999. Petrographic analysis of Bronze Age pottery from Tell Hadidi, Syria, Levant $31,135-147$.

Quinn, P.S., 2013. Ceramic Petrography. The Interpretation of Archaeological Pottery \& Related Artefacts in Thin Section, Archaeopress, Oxford.

Rice, P., 1987. Pottery analysis. A sourcebook, The University of Chicago Press, Chicago and London.

Rothman, M.S., 2001. Uruk Mesopotamia \& its neighbors: cross-cultural interactions in the era of state formation, School of American Research Press, Santa Fe.

Roux, V., 2016. Des céramiques et des hommes. Décoder les assemblages archéologiques, Presses universitaires de Paris Ouest, Nanterre.

Rova, E., 2014. Post-LC 5 North Mesopotamian Developments, in: Lebeau, M. (Ed.), Associated Regional Chronologies for the Ancient Near East Ceramics, Brepols, Turnhout, pp. 1-30.

Rye, O.S., 1976. Keeping your temper under control: materials and the manufacture of Papuan pottery, Archaeology in Oceania 11, 106-137.

Rye, O.S., 1981. Pottery technology: principles and reconstruction, Taraxacum, Washington.

Sakal, F., 2011. Jebel el-Hamam. A new site between Selenkahiye and Emar, in: During, B.S., Wossink, A., Akkermans, P.M.M.G. (Eds.), Correlates of Complexity. Essays in Archaeology and Assyriology dedicated to Diederik J. W. Meijer in Honour of his 65th Birthday, Nederlands Instituut voor het Nabije Oosten, Leiden, pp. 187-192.

Sconzo, P., 2013. Pottery and Potmarks at an Early Urban Settlement of the Middle Euphrates River Valley, Syria. Final Reports of the Syrian-German Excavations at Tell El-'Abd, Ugarit-Verlag.

Sconzo, P., 2015. Ceramics, in: Finkbeiner, U., Novák, M., Sakal, F., Sconzo, P. (Eds.), Associated Regional Chronologies for the Ancient Near East. Middle Euphrates, Brepols, Turnhout, pp. 85-202.

Tite, M.S., 1999. Pottery Production, Distribution, and Consumption-The Contribution of the Physical Sciences, Journal of Archaeological Method and Theory 6, 181-233.

Valdés Pereiro, C., 1995. La cerámica de las tumbas del locus 12 (Tell Qara Qûzâq, Siria, Campaña de 1992), Aula Orientalis 13, 31-58.

Whitbread, I.K., 1989. A Proposal for the Systematic Description of Thin Sections Towards the Study of Ancient Ceramic Technology, in: Maniatis, Y. (Ed.), Archaeometry: Proceedings of the 25th International Symposium, Elsevier, Amsterdam, pp. 127-138. 
Wilkinson, T., 2007. Archaeological regions in the neighbourhood of Carchemish, in: Peltenburg, E. (Ed.), Euphrates River Valley settlement. The Carchemish sector in the third millennium BC, Oxbow Books, Oxford, pp. 27-42.

Wilkinson, T., Miller, N., Reichel, C., Whitcomb, D., 2004. On the margin of the Euphrates: settlement and land use at Tell es-Sweyhat and in the upper Lake Assad area, Syria, The Oriental Institute, Chicago.

Wilkinson, T.J., Philip, G., Bradbury, J., Dunford, R., Donoghue, D., Galiatsatos, N., Lawrence, D., Ricci, A., Smith, S.L., 2014. Contextualizing Early Urbanization: Settlement Cores, Early States and Agro-pastoral Strategies in the Fertile Crescent During the Fourth and Third Millennia BC, Journal of World Prehistory 27, 43-109. 